\title{
A Comparison Study of Math Education and Math Performance between Asian Countries and the United States
}

\section{Wei $\mathrm{MH}^{1 *}$ and Dzeng $\mathrm{H}^{2}$}

${ }^{1}$ National Taichung University of Education, Taiwan

${ }^{2}$ Kaohsiung Medical University, Taiwan

\begin{abstract}
The main purpose of this article is to compare the math education and math performance between Asian Countries and the United States. The authors attempt to analyze from various perspectives, including learning principle and teaching pedagogy, as well as the expectations of the teachers, parents, and students themselves.
\end{abstract}

Keywords: Math education; Math performance; Asian countries

\section{Introduction}

It is well known that many Asian children such as in Taiwan, Japan, Korea, China and Singapore excel in mathematics while American students' performance in mathematics ranks lower than the international average [1]. The difference lies in the different educational systems, learning theories, as well as the expectations of the teachers, parents, and students themselves. Many researchers have indicated that parental beliefs and attitudes affect children's academic achievement, motivation, and sense of competence $[2,3]$.

\section{Asian Parents Placed High Expectations on their Children}

Parental practices and involvement in children's learning are highly correlated with the children's educational achievement [4,5]. In most of the Asian countries, parental practices on children's mathematics achievement are quite stronger. As a matter of fact, Asian parents are more controlling in their interactions with their children, such as how to arrange children's after- school time [6,7]. However, most American parents usually do not put much pressure on the children to excel in math as Asian parents might.

In America, there is not a strong emphasis being placed on the importance of excelling at mathematics. The culture of lower expectations might stem from the school systems having basically set the standard lower for students to achieve from the very beginning, therefore impacting the parents' expectations of their children. However, in most high-academically performing countries of Asia, the national entrance examinations still exist in various levels of education. Thus, the expectations of children academic performance are higher across the board. The Asian parents tend to place more emphasis on being the best, and getting the best grades in any course at school, whereas American parents usually do not demand perfection from their children when it comes to grades.

\section{Learning Principle and Teaching Pedagogy}

Maintaining a positive achievement motivation may be especially important for better achievement in math [8]. Children's math ability are associated with teacher backgrounds and children's individual factors [9]. A teacher's teaching efficacy is important in building students' understanding of math concepts, as well as to inspire their interest of math learning. Math performance in children seems to develop in a cumulative manner, both positively and negatively, depending on previous math learning experiences brought upon by various teaching methods [10]. In the other words, the more successful experiences we offer children in their math classes of their earlier ages, the less negative attitude they have toward math-learning when they grow up [11].

One major difference between Asian and western countries is that western countries emphasize more on children's interest of learning math while oriental countries stress more on children's performance of math. For more than half century, the Asian countries such as Taiwan, China, Korea and Singapore focus on the learning theory of assimilation which highlight the stimulus-response principle, thus computational skills and the speed of solving the math problem become crucial in their teaching pedagogy (Figure 1).

The different principles of education and teaching methods also can be the factor that why American students seem to do more poorly in math compared to Asian students. If an educational system has set a lower standard for students to achieve, one potential problem is that this could cause the students to lose motivation and not feel inspired to learn math. This lowered standard may lead American teachers to adopt a different teaching approach towards math than Asian teachers. Therefore, American teachers may be content to simply follow the textbook, while Asian teachers often believe supplemental teaching material of math is necessary in addition to the textbook (Figure 2).

\section{Supplemental Teaching Program of Asian Society}

Most teachers and parents believe that the students' effort and commitment, such as the amount of time and energy a student spends on the task, do make a difference. Math is often considered as a difficult subject of learning for most students. In the United States, students who fall behind or may not fully understand math concepts, many times do not have supplemental teaching programs to assist them.

In high academically performing Asian countries, under the pressure of competition, most of the parents will send their children to

${ }^{*}$ Corresponding author: Wei $\mathrm{MH}$, National Taichung University of Education, Taiwan, E-mail: weimeihue@yahoo.com.tw

Received September 08, 2013; Accepted September 25, 2014; Published October 15, 2014

Citation: Wei MH, Dzeng H (2014) A Comparison Study of Math Education and Math Performance between Asian Countries and the United States. J Socialomics 3: 111. doi:10.4172/2167-0358.1000111

Copyright: ( 2014 Wei MH, et al. This is an open-access article distributed unde the terms of the Creative Commons Attribution License, which permits unrestricted use, distribution, and reproduction in any medium, provided the original author and source are credited. 


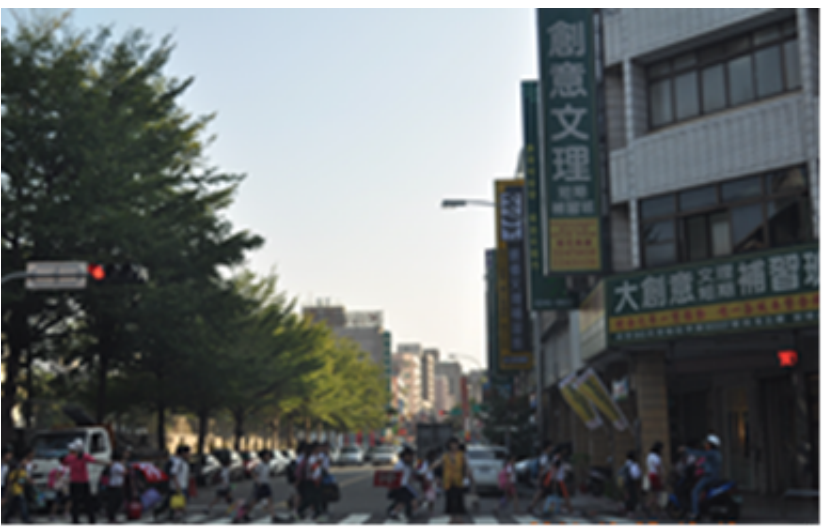

Figure 1: After-school supplemental classes is an unavoidable life experience for most Taiwanese children.

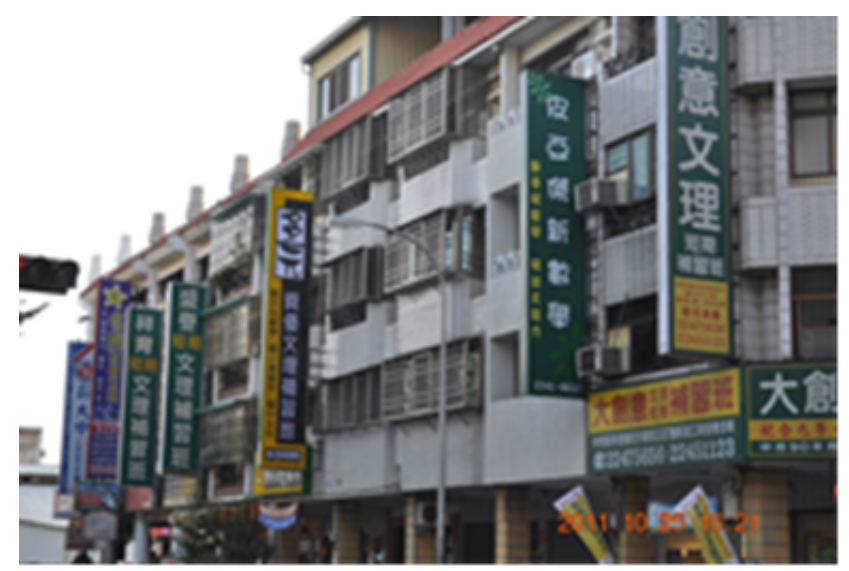

Figure 2: Many Taiwanese elementary school children go straight from school to the after-school supplemental classes.

the private supplemental teaching programs. For those children from wealthy families, very often parents will hire teachers for one-by one tutoring.

Many Asian parents feel that if their children do not participate in the private supplemental teaching programs, they do not fulfill the parents' responsibility. Thus, the after-school supplemental teaching program becomes the experience which almost all Taiwanese, Chinese, and Japanese children have to go through [12].

As a matter of fact, after-school supplemental classes is an unavoidable life experience for most Asian children. Many Asian elementary school children go straight from school to the after-school supplemental classes.

The private supplemental learning program usually can raise up the high-competitive atmosphere which increase children's motivation of learning. The previous study reveals that the performance-oriented and competitive classroom environment tends to foster the acquisition of performance goal orientations, where numerical grades are valued over understanding of concepts [13]. Wang and Tamis-LeMonda's study [14] finds that both Taiwanese mothers and European American mothers rate achievement as very important, but Taiwanese mothers declare this value nearly twice as often as does European Americans. Compared with the American mothers, Taiwanese mothers place greater importance for their children to obtain a graduate-level education and prestigious profession, such as doctor and lawyer [15].

\section{Neighborhood Cultures are Crucial}

According to the eco-cultural theories, parents and families have the strongest influence within interrelated environments on children development [16]. Parents' behaviors and value systems are formed by their socioeconomic backgrounds and by their cultural simulations [17]. Many studies reveal the fact that children's math achievement are significant affected by their Socio-Economic Status (SES), beginning from kindergarten [18]. One fact we might find in various cultures is that children from lower social economic status, might not place as much weight on being a great math student.

The previous studies have shown that neighborhood culture have been linked to parenting features such as parental role commitment, parenting styles, and in-home learning strategies [19]. As a matter of fact, neighborhood quality can predict parental involvement with children's learning behavior in the home [20,21]. The influence of neighborhood culture on children's academic achievement is much stronger in American children than in Asian children. The major reason is the difference in household income and the high tuition policy of the United States, in comparison to most Asian countries. In addition, Asian children can participate in the National Entrance Exam to get into affordable public schools to study.

\section{International Recognition of Mathematic Achievement}

Many Nobel Prize winners are Americans, even though Asian students do receive international recognition in math through tests, however this does not translate into winning prestigious competitions like the Nobel Prize in adulthood. One reason could be that Asian culture over emphasize the performance, which might lead to superficial learning strategies and maladaptive achievement behavior [22-24], such as lack of the motivation to comprehend the concept and only applying strategy or skill to get the correct answer. Another reason could partially stem from the Asian cultural tendency to "keep your head down, and work hard, without drawing attention to yourself". The aforementioned examples might serve as reasons that hold Asians back in terms of international recognition.

However, this might not be necessarily true in the society nowadays, as the workplace culture has changed in this past generation. We somehow see many Taiwanese have made themselves famous in all different aspects, and have gained lot of attention in today's international stage.

\section{Conclusion}

In general, the United States implements a constructivist approach which is child-centered, focusing on the process of math learning and the procedure of problem solving. Mathematical games and operation of teaching materials are crucial in math learning. Meanwhile, Asian countries are based on a assimilation learning approach which emphasize the performance of math learning and gaining the correct answer. Written practice and memorization of math formulas are vital to this approach. In fact, these two approaches should integrate together for optimal achievement in math learning. Although it is important to inspire students' motivation in math through games and operation materials, the structured math lessons and repetitive written practice are equally crucial for enhancing students' math capability. 
Citation: Wei MH, Dzeng H (2014) A Comparison Study of Math Education and Math Performance between Asian Countries and the United States. J Socialomics 3: 111. doi:10.4172/2167-0358.1000111

Page 3 of 3

\section{References}

1. Baldi S, Jin Y, Green PJ, Herget D (2007) Highlights from PISA 2006:Performance of U.S. 15-year-old students in science and mathematics literacy in an international context. NCES 2008-016: National Center for Education Statistics.

2. Frome PM, Eccles JS (1998) Parents' influence on children's achievementrelated perceptions, J Pers Soc Psychol 74: 435-452.

3. McGrath EP, Repetti RL (2000) Mother's and father's attitudes toward their children's academic performance and children's perceptions on their academic competence. J Youth Adolescence 29: 713-723.

4. Lareau A (2003) Unequal Childhoods: Class, Race, and Family Life, University of California Press, Berkeley.

5. Ream RK, Palardy GP (2008) Reexamining social class differences in the availability and the educational utility of parental social capital. Am Edu Res J 45: $238-273$

6. Wei $\mathrm{MH}$ and Eisenhart C (2011) Why do Taiwanese children excel at math? Journal of Phi Delta Kappan, Sep. pg: 74-76.

7. Jose PE, Huntsinger CS, Huntsinger PR, Liaw FR (2000) Parental Values and practices relevant to young children's social development in Taiwan and the United States. J Cross Cult Psychol 31: 677-702.

8. Mägi K, Lerkkanen MK, Poikkeus AM, Rasku-Puttonen H, Kikas E (2010). Relations Between Achievement Goal Orientations and Math Achievement in Primary Grades: A Follow-Up Study. Scandinavian. J Educ Res 54: 295-312.

9. Kim S, Chang M, Kim H (2011). Does teacher educational training help the early math skills of English language learners in Head Start? Children and Youth Services Review 33: 732-740.

10. Aunola K, Leskinen E, Lerkkanen M, Nurmi J (2004) Developmental dynamics of math performance from preschool to grade 2. J Educ Psychol 96: 699-713.

11. Mägi K, Lerkkanen MK, Poikkeus AM, Rasku-Puttonen H, Kikas E (2010) Relations Between Achievement Goal Orientations and Math Achievement in Primary Grades: A Follow-Up Study. Scandinavian J Educ Res 54: 295-312.

12. Lackaye TD, Margalit M (2006) Comparisons of achievement, effort, and self- perceptions among students with learning disabilities and their peers from different achievement groups. J Learn Disabil 39: 432-446.

13. Wolters, Christopher A (2004) Advancing achievement goal theory: Using goa structures and goal orientations to predict students' motivation, cognition, and achievement. J Educ Psychol 96: 236-250.

14. Wang S, Tamis-LeMonda CS (2003) Do childrearing values in Taiwan and the United States reflect cultural values of collectivism and individualism? J Cross Cult Psychol 34: 629-642.

15. Suizzo MA, Cheng $C$ (2007) Taiwanese and American mothers' goals and values for their children's futures. Int J Psychol 42: 307-316.

16. Weisner TS (2002) Ecological pathways, family values, and parenting Parenting: Science and Practice, 2: 325-334.

17. LeVine RA (1994) Childcare and culture: Lessons from Africa. New York Cambridge University Press.

18. Lee VE, Burkam DT (2002) Inequality at the starting gate: Social background differences in achievement as children begin school. Washington, DC: Economic Policy Institute.

19. Burton LM, Jarrett RL (2000) In the mix, yet on the margins: the place of families in urban neighborhood and child development research. J Marriage Fam 62: 1114-1135

20. Ceballo R, McLoyd VVC (2002) Social support and parenting in poor dangerous neighborhoods Child Development 73: 1310-1321.

21. Wang AH (2010) Optimizing early Mathematics experiences for children from low-income families: A study on opportunity to learn mathematics. J Early Child Edu 37: 295-302

22. Church MA, Elliot AJ, Gable SL (2001) Perceptions of classroom environment achievement goals, and achievement outcomes. J Edu Psychol 93: 43-54.

23. Middleton MJ, Midgley C (1997) Avoiding the demonstration of lack of ability: An under explored aspect of goal theory. J Edu Psychol 89: 710-718.

24. Skaalvik EM (1997) Self-enhancing and self-defeating ego orientation: Relations with task and avoidance orientation, achievement, self-perceptions, and anxiety. J Edu Psychol 89: 71-81. 